\title{
Quantitative trait loci for resistance to pre-harvest sprouting in US hard white winter wheat Rio Blanco
}

\author{
Shubing Liu • Shibin Cai $\cdot$ Robert Graybosch • \\ Cuixia Chen · Guihua Bai
}

Received: 20 February 2008 / Accepted: 21 May 2008 / Published online: 10 June 2008

(C) Springer-Verlag 2008

\begin{abstract}
Pre-harvest sprouting (PHS) of wheat is a major problem that severely limits the end-use quality of flour in many wheat-growing areas worldwide. To identify quantitative trait loci (QTLs) for PHS resistance, a population of 171 recombinant inbred lines (RILs) was developed from the cross between PHS-resistant white wheat cultivar Rio Blanco and PHS-susceptible white wheat breeding line NW97S186. The population was evaluated for PHS in three greenhouse experiments and one field experiment. After 1,430 pairs of simple sequence repeat (SSR) primers were screened between the two parents and two bulks, 112 polymorphic markers between two bulks were used to screen the RILs. One major QTL, QPhs.pseru-3AS, was identified in the distal region of chromosome 3AS and explained up to $41.0 \%$ of the total phenotypic variation in three greenhouse experiments. One minor QTL, QPhs.pseru-2B.1, was detected in the 2005 and 2006 experiments and for the means over the greenhouse experiments, and explained $5.0-6.4 \%$ of phenotypic variation. Another minor QTL,
\end{abstract}

Communicated by A. Charcosset.

S. Liu $\cdot$ S. Cai · C. Chen

Department of Agronomy,

Kansas State University, Manhattan, KS 66506, USA

S. Cai

Jiangsu Academy of Agricultural Science, Nanjing 210014, China

R. Graybosch

USDA-ARS, 314 Biochem Hall, University of Nebraska, Lincoln, NE 68583, USA

G. Bai $(\square)$

USDA-ARS, Plant Science and Entomology Research Unit, 4008 Throckmorton Hall, Manhattan, KS 66506, USA

e-mail: guihua.bai@ars.usda.gov
QPhs.pseru-2B.2, was detected in only one greenhouse experiment and explained $4.5 \%$ of phenotypic variation for PHS resistance. In another RIL population developed from the cross of Rio Blanco/NW97S078, QPhs.pseru-3AS was significant for all three greenhouse experiments and the means over all greenhouse experiments and explained up to $58.0 \%$ of phenotypic variation. Because Rio Blanco is a popular parent used in many hard winter wheat breeding programs, SSR markers linked to the QTLs have potential for use in high-throughput marker-assisted selection of wheat cultivars with improved PHS resistance as well as fine mapping and map-based cloning of the major QTL QPhs.pseru-3AS.

\section{Introduction}

Pre-harvest sprouting (PHS) in wheat (Triticum aestivum L.) refers to germination of grains in a physiologically mature wheat spike before harvest when prolonged wet weather occurs. Pre-harvest sprouting is mainly due to early breakage of seed dormancy and can lower wheat grain yield significantly through reduced test weight and negatively affect end-use quality of flour products, substantially reducing grain sale price (Bentsink et al. 2006; Groos et al. 2002; Mori et al. 2005). Poor flour quality caused by PHS directly translates to low bread-making quality. Flour from sprouted wheat has decreased thickening power, which limits the varieties of products that can be made, and bread baked from sprouted wheat can have a smaller volume with compact interior structure (Mansour 1993). To breed PHS-resistant cultivars are the most effective way of addressing the problem, thus, PHS-resistant cultivars are highly desirable in wheat growing areas where long periods of wet weather occur frequently during harvest. 
Seed dormancy is considered the major component of genetic variation for PHS of cereal crops (Bewley and Black 1982). Seed dormancy and PHS in Arabidopsis, wheat, barley, rice, and sorghum are expressed as quantitative traits that are strongly influenced by environments as well as interactions between genotype and environment (Alonso-Blanco et al. 2003; Anderson et al. 1993; Gu et al. 2004; Kato et al. 2001; Lijavetzky et al. 2000). Red color pericarp/testa has been associated with longer seed dormancy and/or PHS resistance in crops, and red grain wheat usually has a higher level of PHS resistance than white wheat (Debeaujon et al. 2000; Gfeller and Svejda 1960; Seshu and Sorrells 1986). Therefore, PHS resistance also has been associated with the red grain color genes (Red), and red grain color has been used as a marker to select for PHS-resistant wheat in some wheat breeding programs (Gale and Leuton 1987; Gfeller and Svejda 1960; Groos et al. 2002). The Red genes as homoeologous loci have been located on the long arms of chromosome group 3 by studying populations derived from crosses between PHSresistant red wheat and PHS-susceptible white wheat, and flanking markers for some of the homoeologous $R$ genes have been reported (Flintham and Gale 1996; Groos et al. 2002; Kulwal et al. 2004, 2005; Nelson et al. 1995). Flintham et al. (1999) demonstrated direct effects of these Red genes on seed dormancy. However, it is still unclear whether the association between PHS and grain color is due to a pleiotropic effect of the Red genes or genetic linkage between the Red and PHS-resistance genes.

White wheats have two advantages over red wheats: lighter flour color and higher flour yield. White wheats are used in domestic production of whole wheat breads and are the preferred wheat of commerce in a number of export markets, especially production of Asian wet noodles. To expand markets for US wheat, hard winter wheat breeders initiated programs to develop hard white wheats in the late 1980s. Tolerance to PHS is an essential trait for successful white wheat marketing. Therefore, PHS-resistant cultivars are highly desirable in PHS-favorable environments such as in the Great Plains of the USA (Morris and Paulsen 1989; $\mathrm{Wu}$ and Carver 1999). Unfortunately, selection for PHS resistance has received little attention in this part of the United States. Because PHS resistance associated with Red genes is not usable for genetic improvement of PHS resistance in white wheat, identifying QTLs for PHS resistance in white wheat will facilitate genetic improvement of PHSresistant white wheat cultivars. Previous studies identified several QTLs for PHS resistance. Anderson et al. (1993) reported several QTLs for PHS resistance on chromosome arms 1AS, 3BL, 4AL, 5DL, and 6BL. Kato et al. (2001) detected a major QTL for PHS resistance on 4AL of a red wheat cultivar, and Mares and Mrva (2001) reported the same QTL, but with smaller effect, for seed dormancy in white wheat. Several recent studies demonstrated that the major QTL on 4AL is present in both white and red wheat cultivars of diverse origins (Chen et al. 2007; Lohwasser et al. 2005; Mares et al. 2005; Torada et al. 2005). Although QTLs for PHS resistance have been identified on many chromosomes in different studies, chromosome $4 \mathrm{~A}$ and all long arms of group 3 chromosomes appear to be more critical for PHS resistance (Flintham and Gale 1996; Groos et al. 2002; Kato et al. 2001; Kulwal et al. 2004; Mori et al. 2005; Osa et al. 2003).

Rio Blanco is a hard white winter wheat (HWWW) with a very high level of PHS resistance from Agripro Biosciences Inc., KS, USA (Wu and Carver 1999) and has been widely used as a parent in HWWW breeding programs (Carver et al. 2003; Haley et al. 2003; Martin et al. 2001). Identifying QTLs and associated molecular markers for PHS resistance in Rio Blanco could facilitate immediate application of marker-assisted selection (MAS) in genetic improvement of PHS resistance in white wheat. Objectives of this study were to identify major QTLs for PHS resistance in Rio Blanco and develop molecular markers closely linked to the QTLs for MAS in HWWW breeding programs.

\section{Materials and methods}

\section{Plant materials}

The initial mapping population of $171 \mathrm{~F}_{6}$ recombinant inbred lines (RILs) was developed by single seed decent from the cross of Rio Blanco/NW97S186 made by USDAARS at the University of Nebraska, Lincoln, NE, USA. Another RIL population (Rio Blanco/NW97S078) from the University of Nebraska was used to verify QTLs identified in the first population. Rio Blanco (OK11252A/W76-1226) is a PHS-resistant HWWW cultivar developed and released by Agripro Biosciences Inc., KS and NW97S186 and NW97S078 are PHS-susceptible HWWW lines developed by USDA-ARS at the University of Nebraska-Lincoln, Lincoln, NE, USA; NW97S186 also is a sister line of the HWWW cultivar Arrowsmith developed by USDA-ARS at the University of Nebraska-Lincoln.

\section{Pre-harvest sprouting evaluation}

Pre-harvest sprouting of both mapping populations (Rio Blanco/NW97S186 and NW97S078/Rio Blanco) and their parents were evaluated in three greenhouse experiments at Manhattan, KS from 2005 to 2007. The RIL population Rio Blanco/NW97S186 also was evaluated in a field experiment at the University of Nebraska Agricultural Research and Development Center, Mead, NE in 2005. In 
the greenhouse experiments, six plants per line were transplanted into a $13-\mathrm{cm} \times 13 \mathrm{~cm}$ tora pot (Hummert Int., St Louis, MO, USA) filled with Metro Mix 360 soil mix (Hummert Int., St Louis, MO, USA) after vernalization at $4^{\circ} \mathrm{C}$ in a growth chamber for 8 weeks and grown on a greenhouse bench at $22^{\circ} \mathrm{C}$ day $/ 15^{\circ} \mathrm{C}$ night temperature with a supplemented daylight of $16 \mathrm{~h}$. Each experiment was arranged in a randomized complete block design with two replicates. Five spikes were harvested from each pot at physiological maturity, which is characterized by loss of green color on the spike (Kulwal et al. 2005). Harvested spikes were air dried for 5 days in the greenhouse at $25 \pm 5^{\circ} \mathrm{C}$ and then stored in a freezer at $-20^{\circ} \mathrm{C}$ to maintain dormancy. After all RILs were harvested, all spikes were taken out from the freezer and air dried again for an additional 2 days on greenhouse benches. Dried spikes were immersed in de-ioned water overnight and then surface sterilized with $0.025 \%$ Terraclor (Southern Agricultural Insecticides Inc., Rubonia, FL, USA) for 3 min before they were incubated in a moist chamber at $20 \pm 2{ }^{\circ} \mathrm{C}$. Wheat spikes were kept at $100 \%$ relative humidity in the moist chamber by running a cool humidifier inside the chamber for $10 \mathrm{~min}$ twice daily. Terraclor solution $(0.025 \%)$ was sprayed on the wheat spikes using a hand mister to control fungal contamination when needed. After 7 days of incubation, geminated spikes were dried at $100^{\circ} \mathrm{C}$ for $2 \mathrm{~h}$ and then at $80^{\circ} \mathrm{C}$ for $12 \mathrm{~h}$ in an oven. Dried spikes were threshed by hand, and germinated and non-germinated kernels in each spike were counted. Percentage of germinated kernels in a spike was used as phenotypic data for PHS-resistance QTL analysis.

In the field experiment, RILs and their parents were seeded in un-replicated four-row, $5 \mathrm{~m}^{2}$ plots at Mead, NE, USA. Plots were trimmed to $2.9 \mathrm{~m}^{2}$ before harvest. At physiological maturity, 20 heads per plot were harvested, dried for 7 days in a greenhouse, and then stored at $-20^{\circ} \mathrm{C}$ until evaluation. Sprouting resistance was assessed by placing ten heads per plot in a misting chamber set with a diurnal temperature regime of $21^{\circ} \mathrm{C}$ day $/ 16^{\circ} \mathrm{C}$ night. Heads were kept moist by applying $20 \mathrm{~min}$ of misting six times daily at 4-h intervals. After 7 days, heads were removed and assigned a sprouting score ranging from 0 to $100 \%$, with $0=$ no seed sprouted and, $100 \%=$ all seeds sprouted in a spike. The experiment was run in duplicate, and a mean score was calculated for each sample.

\section{SSR analysis}

Leaf tissue was harvested at the three-leaf stage, dried in a freezer dryer (ThermoSavant, Holbrook, NY, USA) for 3 days, and ground to fine powder in a Mixer Mill (Retsch $\mathrm{GmbH}$, Haan, Germany) for $3 \mathrm{~min}$ at 30 times per second with the aid of a 3.2-mm metal bead in each tube. DNA was isolated using a modified CTAB method (Saghai-Maroof et al. 1984).

Bulked segregant analysis was used to screen potential polymorphic simple sequence repeat (SSR) markers associated with PHS resistance. The two bulks consisted of five highly PHS-resistant RILs and five highly PHS-sensitive RILs, respectively, from the RIL population of Rio Blanco/ NW97S186. A total of 1,430 SSR primer pairs were screened between parents and bulks, which included BARC (Song et al. 2005), GWM (Röder et al. 1998), WMC (Somers et al. 2004), GDM (Pestsova et al. 2000), CFA, CFD (Guyomarc'h et al. 2002; Sourdille et al. 2003), DUP (Eujayl et al. 2002), and KSM primers developed at Kansas State University, Manhattan, KS, USA. Polymorphic markers between the bulks were analyzed further in the RIL population. A $12-\mu \mathrm{l}$ PCR mixture containing $40 \mathrm{ng}$ of template DNA, $1 \mathrm{mM}$ each of reverse and M13-tailed forward primers, 1 pmole fluorescence-labeled M13 primer, $0.2 \mathrm{mM}$ of each dNTP, 1X PCR buffer, $2.5 \mathrm{mM} \mathrm{MgCl}$, and 0.6 units of Taq polymerase was used for PCR analysis. PCR was performed in a DNA Engine Tetrad Peltier Thermal Cycler (Bio-Rad Lab, Hercules, CA, USA). A touch-town program was used for PCR amplification. The reaction mixture was incubated at $95^{\circ} \mathrm{C}$ for $5 \mathrm{~min}$, then underwent five cycles of $45 \mathrm{~s}$ of denaturing at $96^{\circ} \mathrm{C}, 5 \mathrm{~min}$ of annealing at $68^{\circ} \mathrm{C}$ with a decrease of $2^{\circ} \mathrm{C}$ in each subsequent cycle, and $1 \mathrm{~min}$ of extension at $72^{\circ}$. For another five cycles, the annealing temperature started at $58^{\circ} \mathrm{C}$ for $2 \mathrm{~min}$ with a decrease of $2^{\circ} \mathrm{C}$ for each subsequent cycle. Then, PCR progressed through an additional 25 cycles of $45 \mathrm{~s}$ at $95^{\circ} \mathrm{C}, 2 \mathrm{~min}$ at $50^{\circ} \mathrm{C}$, and $1 \mathrm{~min}$ at $72^{\circ} \mathrm{C}$ with a final extension at $72^{\circ} \mathrm{C}$ for $5 \mathrm{~min}$. Amplified PCR fragments were separated in the ABI Prism 3730 DNA sequencer (Applied Biosystems, Foster City, CA, USA). SSR data were analyzed using GeneMarker software version 1.5 (SoftGenetics LLC, State College, PA, USA).

\section{Data analysis}

The initial genetic linkage map was constructed using marker data from 96 RILs of the Rio Blanco/NW97S186 population and JoinMap version 3.0 (Van Ooijen and Voorrips 2001). Recombination fractions were converted into centiMorgans (cM) using the Kosambi function (Kosambi 1944). The threshold value of logarithm of odd (LOD) score was set at 3.0 to claim linkage between markers with a maximum fraction of recombination at 0.4 . The goodness-of-fit between observed and expected segregation ratios between two alleles was analyzed for each marker locus using a $\chi^{2}$-test. Both simple interval mapping (SIM) and composite interval mapping (CIM) were performed for the data from each individual experiment and from line means for all three-greenhouse experiments using 
WinQTLCart 2.5 (Wang et al. 2005). Likehood ratio (LR) thresholds to declaim significant QTL were set at 10.0 in the Rio Blanco/NW97S186 population and 8.0 in the Rio Blanco/NW97S078 population based on 1,000 permutation tests (Doerge and Churchill 1996). Analysis of variance on seed germination rate from each experiment was performed using the GLM procedure of SAS (SAS Institute Inc, Cary, NC, USA). Total $R^{2}$ was calculated by multiple linear regression using the SAS REG procedure. Designation of QTLs for PHS resistance detected in the present study followed the Inernational Rules of Genetic Nomenclature (http://wheat.pw.usda.gov/ggpages/wgc/98/Intro.htm). QPhs. pseru was designated as the QTL for PHS resistance reported from Plant Science and Entomology Research Unit, USDA/ARS, Manhattan, KS, USA.

\section{Validation of the detected QTLs}

The QTLs detected in the Rio Blanco/NW97S186 population were validated in another population, Rio Blanco/ NW97S078. This population had $80 \mathrm{~F}_{6}$ RILs and was evaluated for PHS resistance in the greenhouse experiments, as described previously for the Rio Blanco/NW97S186 population. All molecular markers that showed significant associations with PHS resistance in the Rio Blanco/NW97S186 population were analyzed in the Rio Blanco/NW97S078 population.

\section{Results}

Pre-harvest sprouting in the parents and RILs

Seed germination rate in a spike was $10.7 \%$ in Rio Blanco, the PHS-resistant parent, and $64.2 \%$ in NW97S186, the PHS-susceptible parent. The wide range in response of the two parents indicated that they were suitable lines for this study. The frequency distribution of PHS ratings for the $\mathrm{F}_{6}$ RILs derived from Rio Blanco/NW97S186 was continuous and showed a nearly bimodal distribution with the larger peak toward Rio Blanco (Fig. 1). This result suggests that both major and minor QTLs might be involved in PHS resistance in the population.

Map construction and QTL analysis

After 1,430 pairs of SSR primers were screened, 324 pairs of SSR primers amplified at least one polymorphic band between Rio Blanco and NW97S186. Among them, 112 primers were polymorphic between the two bulks and were used to analyze a subset of the RILs from Rio Blanco and NW97S186. Linkage analysis of the 112 segregating markers using the RIL population identified nine linkage groups

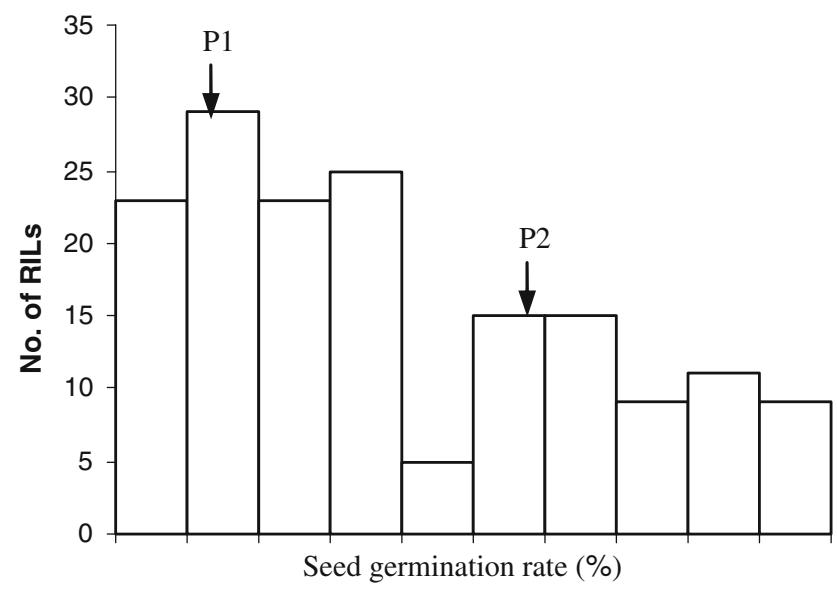

Fig. 1 Distribution of PHS in the $F_{6}$ RIL population Rio Blanco $\times$ NW97S186. The values were the grant means over three experiments in the greenhouses. $\mathrm{P}_{1}$ and $\mathrm{P}_{2}$ represent resistant and sensitive parent, respectively

Table 1 Partial linkage map constructeded using SSR markers and the recombinant inbred population of Rio Blanco/NW97S186

\begin{tabular}{lcc}
\hline Chromosome & No. of markers & Length $(\mathrm{cM})$ \\
\hline 1A & 20 & 105.4 \\
2B & 18 & 100.2 \\
5B & 8 & 58.5 \\
6D & 8 & 35.6 \\
5A & 5 & 5.7 \\
6A & 4 & 24.1 \\
1D & 4 & 22 \\
3A & 4 & 20.1 \\
6B & 3 & 22.5 \\
Total & 74 & 394.1 \\
\hline
\end{tabular}

covering a total genetic distance of $394.1 \mathrm{cM}$ (Table 1). The partial genetic linkage map was used for initial QTL screening.

Single marker analysis based on data from three greenhouse experiments and one field experiment indicated that 22 markers showed a significant association with PHS resistance in 96 RILs of the Rio Blanco/NW97S186 population in at least one experiment. These markers included 15 SSR markers on chromosomes 3AS and 2B. These markers were analyzed further for an additional 75 RILs from the same population. The linkage map constructed using the expanded population of 171 RILs was the same as the map constructed with 96 RILs (data not shown).

Composite interval mapping using the data from 171 RILs identified one to three QTLs for PHS resistance that varied by experiment (Fig. 2; Table 2). Three markers, Xbarc12, Xbarc57, and Xbarc321, showed tight linkage to a QTL on 3AS in all four experiments. This QTL explained $18.5-41.0 \%$ of the phenotypic variation in the three green- 

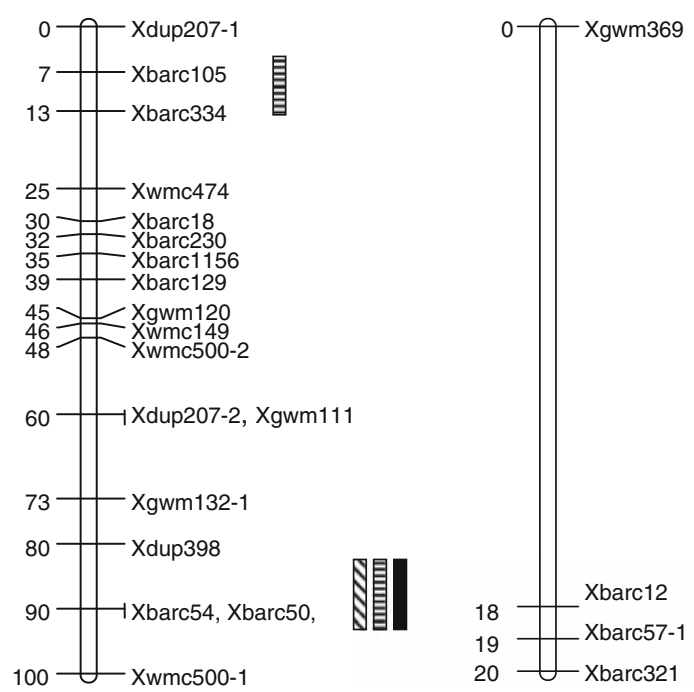

Fig. 2 QTLs detected in the Rio Blanco/NW97S186 population. Bars on the right hand of each linkage group means the QTLs detected in

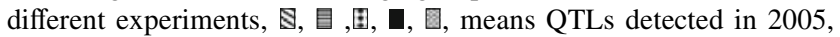
2006 and 2007 greenhouse experiments, mean over three-greenhouse experiments and the 2005 field experiment, respectively

house experiments, $10.1 \%$ of the phenotypic variation in the field experiment, and $41.0 \%$ when the line means from all three greenhouse experiments were analyzed. This QTL, designated as QPhs.pseru-3AS, was most likely a major QTL for PHS resistance in Rio Blanco (Table 2; Fig. 3). SSR marker Xbarc321 had the largest effect on PHS resistance in all four experiments and was the closest marker to QPhs.pseru-3AS. A minor QTL was detected on chromosome 2B for data from the 2005 and 2006 greenhouse

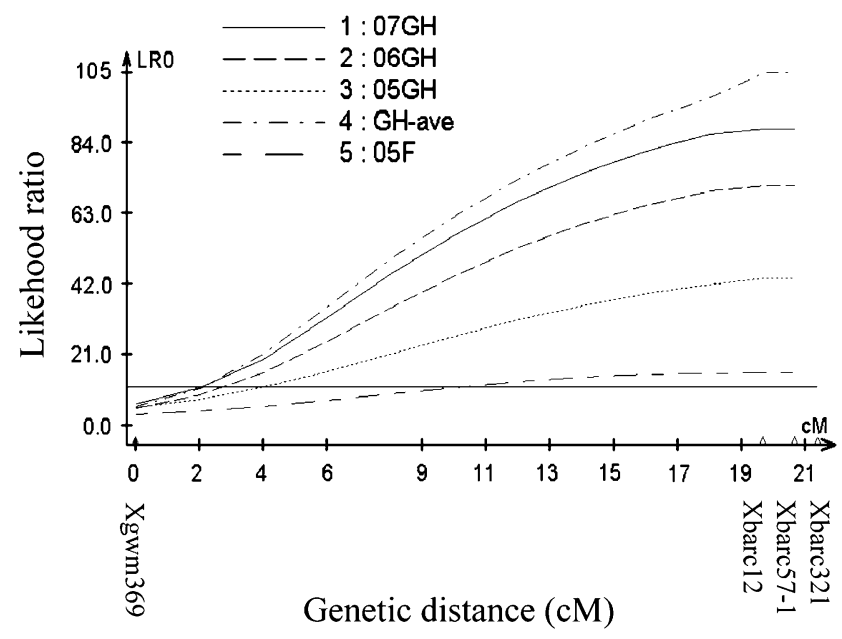

Fig. 3 The Cartographer plot for the major QTL for pre-harvest sprouting resistance on chromosome $3 \mathrm{AS}$ obtained using composite interval mapping (CIM) in four different environments and mean over three greenhouse experiments. The marker names are given at the bottom of the plot

experiments and from the means over three greenhouse experiments. It was flanked by markers Xdup398 and Xbarc54 and designated as QPhs.pseru-2B.1. The second minor QTL, QPhs.pseru-2B.2 that was flanked by the markers Xbarc105 and Xbarc334, was detected in only the 2006 greenhouse experiment and had a $R^{2}$ value of $4.5 \%$. Total phenotypic variation explained by all three QTLs ranged from 33.8 to $45.6 \%$ in the three greenhouse experiments (Table 2).
Table 2 Name, flanking markers, position, likehood ratio (LR), effect $\left(R^{2}\right)$ and additive values of quantitative trait loci (QTL) for pre-harvest spouting resistance in the RIL population of Rio Blanco/NW97S186

\begin{tabular}{|c|c|c|c|c|c|c|}
\hline Experiments $^{\mathrm{a}}$ & QTL name & Flanking markers & QTL Position (cM) & LR & $R^{2}(\%)$ & Additive value $(\%)$ \\
\hline \multirow[t]{2}{*}{$2005 \mathrm{G}$} & QPhs. pseru-3AS & Xbarc12-Xbarc321 & 19.7 & 43.79 & 18.48 & -7.91 \\
\hline & QPhs. pseru-2B-1 & Xdup398-Xbarc54 & 46.78 & 14.34 & 5.54 & -4.27 \\
\hline Total $R^{2}(\%)$ & - & - & - & - & 33.81 & - \\
\hline \multirow[t]{3}{*}{$2006 \mathrm{G}$} & QPhs. pseru-3AS & Xbarc12-Xbarc321 & 20.68 & 71.38 & 31.26 & -16.61 \\
\hline & QPhs. pseru-2B.1 & Xdup398-Xbarc54 & 44.78 & 15.58 & 6.40 & -7.45 \\
\hline & QPhs. pseru-2B.2 & Xbarc105-Xbarc334 & 7.01 & 10.56 & 4.50 & -6.27 \\
\hline Total $R^{2}(\%)$ & - & - & - & - & 45.58 & - \\
\hline $2007 \mathrm{G}$ & QPhs.pseru-3AS & Xbarc12-Xbarc321 & 20.68 & 88.13 & 40.96 & -16.29 \\
\hline \multirow[t]{2}{*}{ Mean-G } & QPhs. pseru-3AS & Xbarc12-Xbarc321 & 20.68 & 104.97 & 41.01 & -15.54 \\
\hline & QPhs. pseru-2B.1 & Xdup398-Xbarc54 & 42.78 & 13.94 & 4.95 & -4.75 \\
\hline Total $R^{2}(\%)$ & - & - & - & - & 49.27 & - \\
\hline $2005 \mathrm{~F}$ & QPhs. pseru-3AS & Xbarc12-Xbarc321 & 20.68 & 15.78 & 10.11 & -4.02 \\
\hline
\end{tabular}

identified using composite interval mapping (CIM) based on phenotypic data collected from 2005 to 2007 greenhouse (Manhattan, KS, USA) and 2005 field (Mead, NE, USA) experiments

${ }^{\mathrm{a}} \mathrm{G}$ represents greenhouse experiments in Manhattan, KS, USA and F represents field experiment in Mead, NE, USA 
Validation of QTLs in the Rio Blanco/NW97S078 population

All 22 markers that showed significant associations with the three QTLs in the Rio Blanco/NW97S186 population were analyzed in the Rio Blanco/NW97S078 population. Among the 22 markers, 17 were polymorphic between Rio Blanco and NW97S078; these were analyzed further in the 80 RILs of Rio Blanco/NW97S078. These markers in the Rio Blanco/NW97S078 population were mapped to the same linkage groups as in the Rio Blanco/NW97S186 population. The QTL on 3AS was detected in all three greenhouse experiments and explained $18.0-34.1 \%$ of the phenotypic variation in three greenhouse experiments and $58.0 \%$ when overall line means from the three greenhouse experiments were analyzed. All other QTLs were not detected in the second population (Table 3 ).

\section{Effectiveness of MAS for PHS resistance}

Because the QPhs.pseru- $3 A S$ was detected in all the experiments, it is likely that this is a stable QTL with a major effect on PHS resistance. The QPhs.pseru-2B.1 QTL was detected in two greenhouse experiments and the mean over three greenhouse experiments. It is possible that this QTL is more stable than the other minor QTL for PHS resistance in Rio Blanco. Effectiveness of the marker loci tightly linked to the two QTLs for MAS to improve PHS resistance was estimated (Table 4). The RILs that contained the 3AS PHS-resistance marker allele Xbarc321 (R) showed the greatest difference in PHS resistance compared with that RILs with the susceptible allele (S) in all greenhouse experiments with significant decreases in seed germination rates ranging from $19.2 \%$ (2005 greenhouse experiment) to $34.4 \%$ (2006 greenhouse experiment) (Table 4). The RILs that carried the resistance marker allele Xbarc54 (R) for QPhs.pseru-2B.1 locus showed lower germination rates than RILs carrying susceptible allele Xbarc54 (S), but the difference was much smaller than that for the Xbarc321 locus, and only 2006 greenhouse data showed a significant difference between the two allelic groups. The RILs carrying both resistance alleles $(\mathrm{R} / \mathrm{R})$ at the two marker loci
Table 4 Allelic effect of markers closely linked to QTLs on 3AS and 2B on pre-harvest sprouting resistance in the wheat population of Rio Blanco/NW97S186 based on data from 2005, 2006, and 2007 greenhouse experiments in Manhattan, KS, USA and a 2006 field experiment in Mead, NE, USA

\begin{tabular}{llcccc}
\hline Locus & Genotype $^{\S}$ & $05 \mathrm{GH}$ & $06 \mathrm{GH}$ & $07 \mathrm{GH}$ & 05 Field \\
\hline Xbarc321 & A (R) & $9.82^{\mathrm{a}}$ & $19.34^{\mathrm{a}}$ & $21.54^{\mathrm{a}}$ & $41.01^{\mathrm{a}}$ \\
& B(S) & $29.06^{\mathrm{b}}$ & $53.73^{\mathrm{b}}$ & $53.69^{\mathrm{b}}$ & $47.61^{\mathrm{a}}$ \\
& dif & 19.24 & 34.39 & 32.15 & 6.60 \\
Xbarc54 & A(R) & $13.43^{\mathrm{a}}$ & $25.66^{\mathrm{a}}$ & $33.74^{\mathrm{a}}$ & $44.29^{\mathrm{a}}$ \\
& B(S) & $21.56^{\mathrm{a}}$ & $39.56^{\mathrm{b}}$ & $37.21^{\mathrm{a}}$ & $45.61^{\mathrm{a}}$ \\
& dif & 8.13 & 13.90 & 3.47 & 1.32 \\
Xbarc321/ & A/A (R/R) & $7.03^{\mathrm{a}}$ & $12.50^{\mathrm{a}}$ & $20.56^{\mathrm{a}}$ & $39.77^{\mathrm{a}}$ \\
Xbarc54 & A/B (R/S) & $12.55^{\mathrm{a}}$ & $25.25^{\mathrm{a}}$ & $22.77^{\mathrm{a}}$ & $42.90^{\mathrm{a}, \mathrm{b}}$ \\
& B/A (S/R) & $22.36^{\mathrm{b}}$ & $43.19^{\mathrm{b}}$ & $46.89^{\mathrm{b}}$ & $47.66^{\mathrm{b}}$ \\
& B/B (S/S) & $36.03^{\mathrm{c}}$ & $63.45^{\mathrm{c}}$ & $60.30^{\mathrm{c}}$ & $48.03^{\mathrm{b}}$ \\
& dif & 29.0 & 50.95 & 39.74 & 8.26 \\
\hline
\end{tabular}

$\S \mathrm{A}$ and B represent the resistant (R) and susceptible (S) alleles of a marker locus from Rio Blanco and NW97S186, respectively, and dif $=$ phenotypic difference between means of two contrasting genotypes

a,b,c Within columns, different letters indicate significant difference at $P<0.05$

showed a greater decrease in seed germination rate than RILs that carried only one or none of the two resistance alleles.

\section{Discussion}

The most effective way to minimize losses caused by PHS is to grow cultivars that have delayed germination time and reduced germination rate when long periods of wet weather occur between plant maturity and harvest. However, progress in genetic improvement of PHS resistance in wheat using classical methods is slow due to complexity in PHS phenotyping. Suitable weather for PHS evaluation is not always available, and setting up controlled environments for large-scale PHS field screening is costly and difficult. In addition, a screening nursery with constant high moisture also induces various diseases that will interfere with the

Table 3 Name, flanking markers, position, likehood ratio (LR), effect $\left(R^{2}\right)$ and additive values of quantitative trait loci (QTLs) detected in the population of Rio Blanco/NW97S078 based on greenhouse experiments in Manhatan, KS, USA

\begin{tabular}{llllrrr}
\hline Experiments $^{\mathrm{a}}$ & QTL name & Flanking markers & Position (cM) & LR & $\begin{array}{c}R^{2}(\%) \\
\text { Additive } \\
\text { value }(\%)\end{array}$ \\
\hline $2005 \mathrm{G}$ & QPhs. pseru-3AS & Xgwm369-Xbarc12 & 13.90 & 13.55 & 17.97 \\
$2006 \mathrm{G}$ & QPhs. pseru-3AS & Xgwm369-Xbarc12 & 12.01 & 27.25 & 34.12 & -12.74 \\
$2007 \mathrm{G}$ & QPhs. pseru-3AS & Xgwm369-Xbarc12 & 10.01 & 21.44 & 31.00 & -10.60 \\
Mean-G & QPhs. pseru-3AS & Xgwm369-Xbarc12 & 10.01 & 41.91 & 58.02 \\
\hline
\end{tabular}

${ }^{a} \mathrm{G}$ represents greenhouse experiments in Manhattan, KS, USA 
accuracy of PHS evaluation. In field conditions, extreme hot weather during maturity can kill late matured plants, which introduces a significant amount of non-genetic variation in germination rates between genotypes due to nonuniform maturity. Several factors, including seed dormancy, seed color, and other morphological characteristics, contribute to PHS resistance and complicate the phenotypic selection process under field conditions. Therefore, MAS might be able to improve selection efficiency and expedite the breeding process. Identification of QTLs and associated markers is the first step toward MAS, and fine mapping and map-based cloning of the QTL. One major QTL on 3AS was consistently significant across all environments tested, indicating this QTL is a stable QTL for PHS resistance in Rio Blanco. However, other QTLs were detected in only the greenhouse experiments. This could be due to the larger environmental variance in field grown plants compared with that of greenhouse grown plants. Also, phenotypic variation explained by the $Q P h s . p s e r u-3 A S$ from the field experiment was much smaller than that from the greenhouse experiments. These results further indicate that accurate evaluation of PHS in field-grown plants is difficult and affected by many non-genetic factors. In addition, it is more difficult to control physiological maturity and harvest time in field experiments. Therefore, evaluation of PHS resistance in greenhouse conditions could provide more accurate data for QTL identification, especially for QTLs with a minor effect.

Genes on the long arms of group 3 chromosomes of red wheat have long been associated with PHS resistance (Flintham and Gale 1996; Nelson et al. 1995). Further research demonstrated that QTLs for PHS resistance on the long arms of group 3 chromosomes co-segregated with the Red genes (Groos et al. 2002; Kulwal et al. 2004, 2005). Although it is unclear whether the association between PHS-resistance QTLs and Red genes is due to a pleiotropic effect of the Red genes or the linkage of Red genes and PHS-resistance QTLs. PHS-resistance genes that were associated with red seed color cannot be used to improve PHS resistance in white wheat. Therefore, it is important to identify QTLs for PHS resistance in white wheat that are independent of any grain color gene. Recently, QTLs from white wheat germplasm have received increased attention. A major QTL on 4AL has been reported in white wheat from China and Africa (Chen et al. 2007; Mares et al. 2005). In another study, two markers, Xbarc55 and Xbcd1434, were found to be associated with PHS resistance in a U.S. white wheat cultivar Clark Cream (http:// maswheat.ucdavis.edu/protocols/PHS). These QTLs were derived from white wheat cultivars and are not related to any Red genes; therefore, they can be used to breed white wheat for improved PHS resistance. Several recent studies demonstrated a major QTL for PHS on the short arm of 3A of the Japanese red wheat cultivar Zen (Miura et al. 2002; Mori et al. 2005; Osa et al. 2003), but whether it exists in white wheat remains unknown. In the current study, one major QTL, QPhs.pseru-3AS, was repeatedly detected on chromosome $3 \mathrm{~A}$ of a white wheat cultivar Rio Blanco. Therefore, this QTL is not linked to red seed color and is independent from the Red gene. The QTL QPhs.ocs-3Al on 3AS from red wheat cultivar Zen (Mori et al. 2005) is about $2 \mathrm{cM}$ distal to QPhs.pseru-3AS from Rio Blanco identified in this study according to Xbarc321 that is a closely linked marker to both QTLs (Song et al. 2005), thus they could be the same QTL. The discrepancy in locations of the two QTLs could be due to the difference in genetic backgrounds and environmental conditions for PHS evaluation. This study is the first to identify the major QTL for PHS resistance on 3AS from white wheat. Direct transfer of QPhs.pseru-3AS from white wheat will avoid interference of Red genes-associated PHS resistance.

The QTL QPhs.pseru-3AS was significant in three greenhouse experiments and one field experiment and explained a large portion of phenotypic variation. Therefore, it is a major QTL with a stable effect on PHS resistance. Furthermore, this QTL also was validated in another population (Rio Blanco/NW97S078) and explained up to $58.02 \%$ of phenotypic variation in the greenhouse experiments. Rio Blanco is a hard winter wheat with many improved agronomic traits and has been used widely as a parent in U.S. hard winter wheat breeding programs (Carver et al. 2003; Haley et al. 2003; Martin et al. 2001; Wu and Carver 1999). Therefore, markers for QPhs.pseru$3 A S$ can be immediately applied in MAS for hard white wheat. In this study, three SSR markers, Xbarc12, Xbarc57 and Xbarc321, closely linked to QPhs.pseru-3AS were identified and they were linked to each other within $1 \mathrm{cM}$ in genetic distance in Rio Blanco, these markers are breederfriendly markers and will significantly facilitate deployment of the major QTL in white wheat breeding programs. Among the three SSR markers we detected, Xbarc321 appeared to have the largest effect and is a good candidate marker for MAS of QPhs.pseru-3AS.

Besides the major QTL on 3AS, two minor QTLs also were detected in some of the experiments. One minor QTL, QPhs.pseru-2B.1, flanked by marker interval Xdup398Xbarc54 was detected in the 2005 and 2006 greenhouse experiments and in the mean data over the three greenhouse experiments. This QTL appeared to have a more consistent effect than the other minor QTL. This locus is near marker Xbarc55 (Somers et al. 2004), which was reported to be linked to the QTL in cultivar Clark Cream (http://maswheat.ucdavis.edu/protocols/PHS). Thus, it is possible that they share the same locus. The smaller effect of the QTL detected in this study could be due to lack of closely linked markers to the QTL or to a different allele. The other minor 
QTL, QPhs.pseru-2B.2, was detected in only a single experiment and might not be consistent in effect across environments. This QTL was new and has not been reported previously. Further investigation on effects of this QTL is needed before it can be used in breeding.

Germination rate of the RILs carrying the PHS-resistance allele Xbarc54 for QTL QPhs.pseru-2B.1 also showed differences from the RILs carrying the susceptible allele, but the differences are much smaller than for marker Xbarc321 and were significant in only the 2006 greenhouse experiment. When the two QTLs were combined, PHS resistance of plants with both resistant alleles was much higher than that of those carrying only a single QTL (Table 4). Results indicated that MAS for the QPhs.pseru$3 A S$ using marker Xbarc321 will significantly improve PHS resistance. However, MAS for both QPhs.pseru-3AS and $2 \mathrm{~B}$ might be able to achieve a higher level of PHS resistance than from selection for the QPhs.pseru-3AS alone.

Acknowledgments Research is partly funded by the National Research Initiative of the USDA Cooperative State Research, Education and Extension Service, Coordinated Agricultural Project grant number 2006-55606-16629. Mention of trade names or commercial products in this article is solely for the purpose of providing specific information and does not imply recommendation or endorsement by the US Department of Agriculture. This is contribution No. 08-216-J from the Kansas Agricultural Experiment Station, Manhattan, KS, USA.

\section{References}

Alonso-Blanco C, Bentsink L, Hanhart CJ, Vries HBE, Koornneef M (2003) Analysis of natural allelic variation at seed dormancy loci of Arabidopsis thaliana. Genetics 164:711-729

Anderson JA, Sorrells ME, Tanksley SD (1993) RFLP analysis of genomic regions associated with resistance to pre-harvest sprouting in wheat. Crop Sci 33:453-459

Bentsink L, Jowett J, Hanhart CJ, Koornneef M (2006) Cloning of $D O G 1$, a quantitative trait locus controlling seed dormancy in Arabidopsis. Proc Natl Acad Sci USA 103:17042-17047

Bewley JD, Black M (1982) Physiological and biochemistry of seeds in relation to germination, vol 2. Springer, Heidelberg, pp 61-81

Carver BF, Krenzer EG, Klatt AR, Guenzi AC, Martin BC, Bai G-H (2003) Registration of 'Intrada' wheat. Crop Sci 43:1135-1136

Chen C-X, Cai S-B, Bai G-H (2007) A major QTL controlling seed dormancy and pre- harvest sprouting resistance on chromosome 4A in a Chinese wheat landrace. Mol Breed. doi:10.1007/s110329135-5

Debeaujon IKM, Leon-Klooterziel KM, Koornneef M (2000) Influence of the testa on seed dormancy, germination, and longevity in Arabidopsis. Plant Physiol 122:403-413

Doerge RW, Churchill GA (1996) Permutation tests for multiple loci affecting a quantitative character. Genetics 142:285-294

Eujayl I, Sorrells ME, Baum M, Wolters P, Powell W (2002) Isolation of EST-derived microsatellite markers for genotyping the A and B genomes of wheat. Theor Appl Genet 104:399-407

Flintham JE, Gale MD (1996) Dormancy gene maps in homoeologous cereal genomes. In: Noda K, Mares DJ (eds) Pre-harvest sprouting in cereals. Centre for Academic Societies, Japan, pp 143-149
Flintham JE, Adlam R, Gale MD (1999) Seed coat and embryo dormancy in wheat. In: Weipert D (ed) Eighth international symposium on pre-harvest sprouting in cereals. Association of Cereal Research, Detmold, pp 67-76

Gale MD, Leuton JR (1987) Preharvest sprouting in wheat: a complex genetic and physiology problem affecting bread making quality in UK wheat. Aspects Appl Biol 15:115-124

Gfeller F, Svejda F (1960) Inheritance of post-harvest seed dormancy and kernel color in spring wheat lines. Can J Plant Sci 40:1-6

Groos C, Gay G, Perretant MR, Gervais L, Bernard M, Dedryver F, Charmet G (2002) Study of the relationship between pre-harvest sprouting and grain color by quantitative trait loci analysis in a white-red grain bread wheat cross. Theor Appl Genet 104:39-47

Gu XY, Kianian SF, Foley ME (2004) Multiple loci and epitases control genetic variation for seed dormancy in weedy rice (Oryza sativa). Genetics 166:1503-1516

Guyomarc'h H, Sourdille P, Edwards KJ, Bernard M (2002) Studies of the transferability of microsatellite derived from Triticum taushchii to hexaploid wheat and to diploid related species using amplification, hybridization and sequence comparisons. Theor Appl Genet 105:736-744

Haley SD, Quick JS, Stromberger JA, Clayshulter SR, Clifford BL, Johnson JJ (2003) Registration of 'Avalanche' wheat. Crop Sci 43:432

Kato K, Nakamura W, Tabiki T, Miura H, Sawada S (2001) Detection of loci controlling seed dormancy on group 4 chromosomes of wheat and comparative mapping with rice and barley genomes. Theor Appl Genet 102:980-985

Kosambi DD (1944) The estimation of map distances from recombination values. Ann Eugen 12:172-175

Kulwal PL, Singh R, Balyan HS, Gupta PK (2004) Genetic basis of pre-harvest sprouting tolerance using single-locus and two-locus QTL analyses in bread wheat. Funct Integr Genomics 4:94-101

Kulwal PL, Kumar N, Gaur A, Khurana P, Khurana JP, Tyagi AK, Balyan HS, Gupta PK (2005) Mapping of a major QTL for pre-harvest sprouting tolerance on chromosome $3 \mathrm{~A}$ in bread wheat. Theor Appl Genet 111:1052-1059

Lijavetzky D, Martinez MC, Carrari F, Hopp HE (2000) QTL analysis and mapping of pre-harvest sprouting resistance in sorgahum. Euphytica 112:125-135

Lohwasser U, Röder M, Böner A (2005) QTL mapping of the domestication traits pre-harvest sprouting and dormancy in wheat. Euphytica 143:247-249

Mansour K (1993) Sprout damage in wheat and its effect on wheat flour products. In: Walker-Simmons MK, Ried JL (eds) Pre-harvest sprouting in cereals, 1992. American Association of Cereal Chemistry Press, St Paul, pp 8-9

Mares DJ, Mrva K (2001) Mapping quantitative trait loci associated with variation in grain dormancy in Australian wheat. Aust J Agric Res 52:1257-1265

Mares D, Mrva K, Cheong J, Williams K, Watson B, Storlie E, Sutherland M, Zou Y (2005) A QTL located on chromosome 4A associated with dormancy in white- and red-grained wheats of diverse origin. Theor Appl Genet 111:1357-1364

Martin TJ, Scifers DL, Harvey TL (2001) Registration of Trego wheat. Crop Sci 41:929-930

Miura H, Sato N, Kato K, Amano Y (2002) Detection of chromosomes carrying genes for seed dormancy of wheat using the backcross reciprocal monosomic method. Plant Breed 121:394-399

Mori M, Uchino N, Chono M, Kato K, Miura H (2005) Mapping QTLs for grain dormancy on wheat chromosome $3 \mathrm{~A}$ and group 4 chromosomes, and their combined effect. Theor Appl Genet 110:1315-1323

Morris CF, Paulsen GM (1989) Registration of five preharvest sprouting-resistant hard white winter wheat germplasm. Crop Sci 29:246-247 
Nelson JC, Van Deynze AE, Autrique E, Sorrells ME, Yun HL, Negre S, Bernard M, Leroy P (1995) Molecular mapping of wheat: homoeologous group 3. Genome 38:525-533

Osa M, Kato K, Mori M, Shindo C, Torada A, Miura H (2003) Mapping QTLs for seed dormancy and the Vpl homologue on chromosome 3A in wheat. Theor Appl Genet 106:1491-1496

Pestsova EG, Ganal MW, Röder MS (2000) Isolation and mapping of microsatellite markers specific for the D-genome of bread wheat. Genome 43:689-697

Röder MS, Korzun V, Wendehake K, Plaschke J, Tixier MH, Leroy P, Ganal MW (1998) A microsatellite map of wheat. Genetics 149:2007-2023

Saghai-Maroof MA, Soliman K, Jorgensen RA, Allard RW (1984) Ribosomal DNA spacer-length polymorphisms in barley: Mendelian inheritance, chromosomal location, and population dynamics. Proc Natl Acad Sci USA 81:8014-8018

Seshu DV, Sorrells ME (1986) Genetic studies on seed dormancy in rice. In: Rice genetics. IRRI, Manila, pp 369-382

Somers DJ, Isaac P, Edwards K (2004) A high-density wheat microsatellite consensus map for bread wheat (Triticum aestivum L.). Theor Appl Genet 109:1105-1114
Song QJ, Shi JR, Singh S, Fickus EW, Costa JM, Lewis J, Gill BS, Ward R, Cregan PB (2005) Development and mapping of microsatellite (SSR) markers in wheat. Theor Appl Genet 110:550-560

Sourdille P, Cadalen T, Guyomarc'h H, Snape JW, Perretant MR, Charmet G, Boeuf C, Bernard S, Bernard M (2003) An update of the Courtot/Chinese Spring intervarietal molecular marker linkage map for the QTL detection of agronomic traits in wheat. Theor Appl Genet 106:530-538

Torada A, Ikegnchi S, Koike M (2005) Mapping and validation of PCR-based markers associated with a major QTL for seed dormancy in wheat. Euphytica 143:251-255

Van Ooijen JW, Voorrips RE (2001) JionMap version 3.0: Software for the calculation of genetic linkage maps

Wang S, Basten CJ, Zeng ZB (2005) Windows QTL Cartographer 2.5. Departmentof Statistics, North Carolina State University, Raliegh. http://statgen.ncsu.edu/qtlcart/WQTLCart.htm

Wu J, Carver BF (1999) Sprout damage and preharvest sprout resistance in hard white winter wheat. Crop Sci 39:41-447 